\title{
Is thiopurine therapy in ulcerative colitis as effective as in Crohn's disease?
} S Ghosh, R Chaudhary, M Carpani, R J Playford

There is evidence in support of the use of azathioprine in steroid dependent ulcerative colitis patients, confirming the steroid sparing effect of azathioprine

$\mathrm{T}$ he use of azathioprine or 6-mercaptopurine for maintaining remission in Crohn's disease patients who are steroid dependent or resistant is unequivocally supported by evidence from randomised controlled clinical trials. The same, however, cannot be said for the use of immunomodulator therapy in ulcerative colitis (UC). Trials are scanty, small in size, conflicting in results, and clinical practice is dominated by support from low quality evidence from open series reports. In addition, outcome measures used in different trials vary considerably, and the tools used to assess clinical disease activity are numerous and diverse.

In the first randomised controlled trial, conducted way back in 1974 by Jewell and Truelove, ${ }^{1}$ a two by three stratification was used. Inpatients or outpatients with active UC were stratified into first attack, short history (less than five years), and long history (more than five years). The acute episode was treated with corticosteroids, either $20 \mathrm{mg}$ oral prednisolone plus steroid enemas for outpatients or $40 \mathrm{mg}$ prednisolone 21-phosphate with rectal hydrocortisone for inpatients. Azathioprine was added immediately at a dose of $2.5 \mathrm{mg} / \mathrm{kg}$. In the first 40 patients, the azathioprine dose was reduced after three months to $1.5-2.0 \mathrm{mg} / \mathrm{kg}$ whereas in the next 40 patients the dose was maintained at $2.5 \mathrm{mg} / \mathrm{kg}$ throughout the trial period of one year. It was not surprising that azathioprine was of no value in induction of remission as the end point was at one month after commencement of azathioprine. As maintenance therapy, azathioprine lacked value in patients being treated for the first attack of UC. Although there was a trend towards some benefit in patients with established UC who had relapsed, this was not statistically significant. As the numbers were small, type II error was quite possible. Nevertheless, it was concluded that azathioprine was less valuable as a maintenance therapy than sulphasalazine.

Subsequently, several other studies have been performed which, unfortunately, have not necessarily clarified the situation. In a small, double blind, randomised, controlled trial in 20 steroid naïve active UC patients for three months, azathioprine $2.5 \mathrm{mg} / \mathrm{kg}$ was, however, as effective as sulphasalazine $65 \mathrm{mg} / \mathrm{kg}$ in controlling disease. ${ }^{2}$ In a randomised controlled trial comparing azathioprine $\quad 2.0-2.5 \mathrm{mg} / \mathrm{kg}$

$(24$ patients) with placebo (20 patients) added to conventional corticosteroid therapy, clinical disease activity scores in the two groups showed no significant difference at three or six months although azathioprine did exert a steroid sparing effect. ${ }^{3}$ A small open randomised study from India on 25 active UC patients treated with $1 \mathrm{mg} / \mathrm{kg}$ steroids, azathioprine, or sulphasalazine maintenance was associated with similar relapse rates over an 18 month therapy period. ${ }^{4}$ Therefore, these studies did not provide entirely convincing evidence of benefit of maintenance therapy with azathioprine in UC, although none of the studies recruited steroid dependent or resistant UC patients, a more relevant clinical indication. In the first double blind randomised controlled trial in steroid dependent UC patients, treatment with azathioprine $1.5 \mathrm{mg} / \mathrm{kg}$ $(\mathrm{n}=16)$ was compared with placebo $(\mathrm{n}=14)$ for six months. No symptomatic or proctoscopic differences were observed between the two groups although steroid dose was lower in the azathioprine group at study termination compared with the placebo group. ${ }^{5}$ The dose of azathioprine in this study was low compared with the currently accepted optimal dose and type II error cannot be excluded.

Things began to clarify with the publication of a pivotal study that established the use of azathioprine in UC. This trial took the form of a double blind placebo controlled trial of withdrawal or continuation of azathioprine and was conducted in the UK. ${ }^{6}$ Patients with UC on azathioprine for at least six months and in remission for at least two months were recruited. The one year relapse rate was $36 \%$ for patients continuing azathioprine $(n=33)$, significantly less than $59 \%$ for those on placebo $(\mathrm{n}=34)$. Mean azathioprine dose was $100 \mathrm{mg} /$ day and most patients were also on aminosalicylates. This study established that, in patients maintained on azathioprine for a mean duration of approximately just over one and half years, withdrawal of azathioprine leads to increased relapses compared with continuation of the drug. This study therefore is relevant to a selected group of patients who have poorly controlled UC, who have a good response to azathioprine, and who tolerate it well. This study prompted the more widespread use of azathioprine in poorly controlled UC. However, although this study provides indirect evidence of the benefit of azathioprine maintenance in UC, it does not provide direct evidence of the benefit of azathioprine in inducing and maintaining poorly controlled UC patients in remission.

Retrospective or open label analysis has suggested response rates of $84 \%^{7}$ and $63 \%^{8}$ as well as remission rates of $65 \%{ }^{9}$ and $69 \%{ }^{10}$ from single tertiary care centres although the definitions of response and remission have been inconsistent. In the largest retrospective series analysis from Oxford encompassing 30 years of experience, overall remission rate was $58 \%$ in UC patients $(n=346)$, and duration of azathioprine treatment did not affect relapse rates after discontinuation of therapy. ${ }^{11}$ Retrospective series analysis has also confirmed decreased steroid requirement and clinical relapses in the three years after commencement of azathioprine compared with two years prior to azathioprine. $^{12}$

Two recent studies have provided further evidence in favour of the use of azathioprine in UC. In a Spanish study published last year, 34 patients with UC receiving prednisolone were randomised on a $2: 2: 1$ basis to $1.5 \mathrm{mg} / \mathrm{kg}$ of 6-mercaptopurine, $15 \mathrm{mg} /$ week of methotrexate, or $3 \mathrm{gm} /$ day of 5 -aminosalicylic acid. ${ }^{13}$ All patients who achieved remission over a 30 week treatment period continued into the maintenance phase of the study for 76 weeks. Induction of remission was significantly superior in the azathioprine group compared with the 5 -aminosalicylic acid group $(78.6 \% v$ $25 \%$ ). Maintenance of remission in those who achieved remission was $63.6 \%$ in the azathioprine group compared with none in the 5-aminosalicylic acid group. Methotrexate was inferior to azathioprine in both induction and maintenance of remission. 
Table 1 Summary of studies of azathioprine/6-mercaptopurine in ulcerative colitis

\begin{tabular}{|c|c|c|}
\hline Author (No of patients) & Results & Comments \\
\hline \multicolumn{3}{|c|}{ Randomised, blind, placebo controlled trials } \\
\hline Jewell' $(n=80)$ & $\begin{array}{l}\text { AZA of no benefit in acute flare compared with placebo } \\
\text { (standard steroid course given to all) }\end{array}$ & $\begin{array}{l}\text { Some maintenance benefit in preventing relapse } \\
\text { in established disease noted. }\end{array}$ \\
\hline Caprilli $^{2}(n=20)$ & $\begin{array}{l}\text { No significant difference between sulphasalazine and AZA in } \\
\text { active colitis }\end{array}$ & $\begin{array}{l}3 \text { month study. Improvement in symptoms and } \\
\text { histology with both drugs. }\end{array}$ \\
\hline Rosenberg $^{5}(30)$ & $\begin{array}{l}\text { No clinical or mucosal improvement with AZA after } 6 \text { months } \\
\text { compared with placebo in chronic UC }\end{array}$ & Dose $1.5 \mathrm{mg} / \mathrm{kg}$. Steroid sparing effect noted. \\
\hline $\operatorname{Kirk}^{3}(n=44)$ & $\begin{array}{l}\text { Significant improvement in chronic UC in AZA group at } 3 \text { and } \\
6 \text { months }\end{array}$ & $\begin{array}{l}\text { Steroid sparing effect noted. No difference in } \\
\text { clinical activity scores between AZA and } \\
\text { placebo }\end{array}$ \\
\hline Hawthorne $^{6}$ (79) & Relapse at 1 year $36 \%$ (AZA) compared with $59 \%$ for placebo & $\begin{array}{l}\text { Placebo controlled withdrawal study following } \\
\text { remission in chronic UC. }\end{array}$ \\
\hline Ardizzone $^{14}(n=72)$ & $\begin{array}{l}\text { Remission at } 6 \text { months was } 53 \% \text { for AZA and } 21 \% \text { for } \\
5 \text {-aminosalicylic acid }\end{array}$ & $\begin{array}{l}\text { All patients on } 40 \mathrm{mg} \text { prednisolone at study } \\
\text { entry. Steroid sparing effect confirmed. } \\
\text { However, investigator blind only. Not double } \\
\text { dummy. }\end{array}$ \\
\hline \multicolumn{3}{|c|}{ Randomised open label studies } \\
\hline Paoluzi ${ }^{10}(42)$ & $\begin{array}{l}69 \% \text { complete remission of steroid dependant/resistant UC at } \\
6 \text { months }\end{array}$ & $\begin{array}{l}\text { Methotrexate used if intolerant to AZA. } \\
\text { Methotrexate relapse rate found to be less than } \\
\text { AZA. }\end{array}$ \\
\hline Sood $^{4}(25)$ & $\begin{array}{l}\text { Relapse rate of AZA comparable with sulphasalazine group in } \\
\text { the maintenance of remission in severe acute newly diagnosed } \\
\text { UC (standard steroid course given to all) }\end{array}$ & $\begin{array}{l}\text { Trend towards earlier treatment failure in AZA } \\
\text { group. }\end{array}$ \\
\hline $\begin{array}{l}\text { Mate-Jimenez }{ }^{13} \\
\text { (72 (34 UC/39 CD)) }\end{array}$ & $\begin{array}{l}\text { For steroid dependant UC remission rate was } 79 \% \text { for AZA } \\
\text { (p<0.05), 58\% for methotrexate (NS) compared with } 25 \% \text { for } \\
5 \text { ASA. }\end{array}$ & $\begin{array}{l}\text { Only comparison of AZA with methotrexate in } \\
\text { UC. }\end{array}$ \\
\hline \multicolumn{3}{|l|}{ Retrospective/case series } \\
\hline Adler $^{8}(81)$ & $63 \%$ remission response rate with $6 \mathrm{MP}$ in refractory UC & $\begin{array}{l}\text { In } 48 \% \text { steroids were eliminated for a mean } \\
\text { period of } 19 \text { months. }\end{array}$ \\
\hline George $^{9}(105)$ & $\begin{array}{l}65 \% \text { achieved complete and } 24 \% \text { partial clinical remission } \\
\text { with } 6 \mathrm{MP}\end{array}$ & $\begin{array}{l}\text { Discontinuation of } 6 \mathrm{MP} \text { resulted in a higher } \\
\text { relapse rate compared with those continuing } \\
6 \mathrm{MP} \text {. }\end{array}$ \\
\hline Fernandez-Banares ${ }^{19}(10)$ & $\begin{array}{l}10 \% \text { relapse rate with AZA as maintenance over mean of } \\
16 \text { months in this series }\end{array}$ & $\begin{array}{l}\text { AZA used as maintenance therapy following } \\
\text { intravenous ciclosporin in severe acute UC. }\end{array}$ \\
\hline Ardizzone $^{12}(56)$ & $\begin{array}{l}69 \% \text { steroid resistant/dependant UC in remission and off } \\
\text { steroids at } 3 \text { years with AZA }\end{array}$ & $\begin{array}{l}\text { AZA response associated with steroid } \\
\text { reduction/elimination, reduced colectomy, and } \\
\text { reduced relapse rates. }\end{array}$ \\
\hline $\begin{array}{l}\text { Khan } \\
(111(53 \mathrm{UC} / 58 \mathrm{CD}))\end{array}$ & $\begin{array}{l}\text { Clinical improvement in } 84 \% \text { of IBD patients at } 1 \text { year with AZA, } \\
68 \% \text { of whom were off steroids }\end{array}$ & Relatively low dose of AZA $1.5 \mathrm{mg} / \mathrm{kg}$. \\
\hline $\begin{array}{l}\text { Fraser }^{11} \\
1626(346 \mathrm{UC} / 242 \mathrm{CD} / 4\end{array}$ & $58 \%$ remission rate with $A Z A$ for UC & Relapse rate similar for UC and CD patients. \\
\hline
\end{tabular}

In a further study from Milan reported in this issue of Gut by Ardizzone and colleagues, ${ }^{14} 72$ patients with active steroid dependent UC were randomised (investigator-blind) to azathioprine $2 \mathrm{mg} / \mathrm{kg} /$ day or 5 -aminosalicylic acid $3.2 \mathrm{~g} /$ day for a six month period (see page 47). Clinical and endoscopic remission with discontinuation of steroids was achieved in 53\% of azathioprine treated patients compared with $21 \%$ of 5 -aminosalicylic acid treated patients (intention to treat analysis: odds ratio $4.78 \quad(95 \%$ confidence interval 1.57-14.5). Definition of steroid dependence was standardised and all patients were on the same dose of prednisolone $40 \mathrm{mg} /$ day at study entry. This study provides the best evidence for the efficacy of azathioprine in steroid dependent patients. In addition, the steroid sparing effect of azathioprine in UC was confirmed.

In UC, use of immunomodulator therapy has not been backed up by good randomised controlled trial evidence (table 1). The controlled trial evidence in favour of using methotrexate is poor. ${ }^{13}{ }^{15}$
Retrospective series and audit experience of using methotrexate in UC suggests evidence of moderate efficacy. ${ }^{16}$ The Milan trial reported in this issue of $G u t^{14}$ provides support for the use of azathioprine in steroid dependent UC patients. However, in severely ill UC patients refractory to steroids, azathioprine is likely to be too slow to be of benefit in preventing colectomy. In this scenario, ciclosporin may be used to spare colectomy, but a recent Cochrane Database systematic review concluded that there is limited evidence that ciclosporin is more effective than standard therapy alone for severe UC. ${ }^{18}$ The rapid response is the main attraction for the short term use of ciclosporin but long term benefits are unclear and the potential toxicity profile formidable. Addition of azathioprine to ciclosporin may reduce the propensity for early relapses, at the cost of increasing toxicity, ${ }^{19}{ }^{20}$ but over seven years $58 \%$ of such patients may come to colectomy. ${ }^{21}$ The early experience with infliximab is very promising with respect to avoiding colectomy. ${ }^{22}$
The Milan controlled study has provided much needed evidence in support of the use of azathioprine in steroid dependent UC patients and showed that this strategy is better than using $3.2 \mathrm{~g} /$ day of 5-aminosalicylic acid. This is important as previous evidence supporting such use from randomised controlled trials was limited. Whether using higher doses of 5-aminosalicylic acid in such patients might increase efficacy significantly is unclear at present but would appear unlikely. The evidence supporting the efficacy of methotrexate in UC either for inducing or maintaining remission also remains unconvincing. In steroid resistant patients the options are more limited, especially in severe disease, as azathioprine is too slow in its onset of effect. Ciclosporin, especially in a $2 \mathrm{mg} / \mathrm{kg}$ dose to limit toxicity, may be an option, ${ }^{23}$ although infliximab may turn out to be a more attractive therapy. ${ }^{22}$ Both of these therapies may require concurrent use of azathioprine or 6-mercaptopurine. Leucocyte apheresis is emerging as a further option in need of 
randomised controlled trial evidence. On current evidence, bolstered by the Milan results, the place of azathioprine in the UC management algorithm is probably similar to that in Crohn's disease, although the quality of evidence in the latter is still better. Colectomy is curative of the disease in the former, although often associated with somewhat frequent bowel movements, pouchitis, reduction of fertility in females, and (infrequently) may result in a permanent stoma.

With the rapid emergence of new therapies in inflammatory bowel disease, it is heartening to see evidence for conventional therapies being consolidated, as designing correct management algorithms will depend entirely on the quality of available data. The old adage of "out with the old and in with the new!" should therefore be replaced with "consider the new but don't forget the old (therapies)".

Gut 2006;55:6-8.

doi: 10.1136/gut.2005.074401

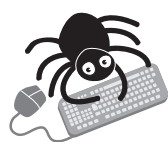

Conflict of interest: declared (the declaration can be viewed on the Gut website at http://www.gutjnl.com/ supplemental).

\section{Authors' affiliations}

\section{S Ghosh, R Chaudhary, R J Playford,}

Imperial College, Hammersmith Hospital,

London, UK

M Carpani, Hammersmith Hospital, London, UK
Correspondence to: Professor S Ghosh, Imperial College London, Hammersmith Hospital, Ducane Rd, London W12 ONN, UK s.ghosh@imperial.ac.uk

\section{REFERENCES}

1 Jewell DP, Truelove SC. Azathioprine in ulcerative colitis: Final report on a controlled therapeutic trial. BMJ 1974;4:627-30.

2 Caprilli R, Carratu R, Babbini M. A double-blind comparison of the effectiveness of azathioprine and sulfasalazine in idiopathic proctocolitis. A preliminary report. Dig Dis Sci 1975;20: 1 15-20.

3 Kirk P, Lennard-Jones JE. Controlled trial of azathioprine in chronic ulcerative colitis. $B M$ 1982;284:1291-2.

4 Sood A, Midha V, Sood N, et al. Role of azathioprine in severe ulcerative colitis: one-year, placebo-controlled, randomized trial. Indian J Gastroenterol 2000;19:14-16

5 Rosenberg JL, Wall AJ, Levin B, et al. A controlled trial of azathioprine in the management of chronic ulcerative colitis. Gastroenterology 1975:69:96-9.

6 Hawthorne AB, Logan RF, Hawkey CJ, et al. Controlled trial of azathioprine withdrawal in ulcerative colitis. BMJ 1992;305:20-2.

7 Khan ZH, Mayberry JF, Spiers N, et al. Retrospective case series analysis of patients with inflammatory bowel disease on azathioprine. Digestion 2000:62:249-54,

8 Adler DJ, Korelitz BI. The therapeutic efficacy of 6-mercaptopurine in refractory ulcerative colitis. Am J Gastroenterol 1990;85:717-22.

9 George J, Present DH, Pou R, et al. The long-term outcome of ulcerative colitis treated with 6mercaptopurine. Am J Gastroenterol 1996;91:1711-14.

10 Paoluzi OA, Pica R, Marcheggiano A, et al. Azathioprine or methotrexate in the treatment of patients with steroid-dependent or steroidresistant ulcerative colitis: results of an open-labe study on efficacy and tolerability in inducing and maintaining remission. Aliment Pharmacol Ther 2002; 16:1751-9.

11 Fraser AG, Orchard TR, Jewell DP. The efficacy of azathioprine for the treatment of inflammatory bowel disease: a 30 year review. Gut 2002;50;485-9.
12 Ardizzone S, Molteni P, Imbesi V, et al. Azathioprine in steroid-resistant and steroiddependent ulcerative colitis. J Clin Gastroenterol 1997:25:330-3.

13 Mate-Jimenez J, Hermida C, Cantero-Perona J, et al. 6-Mercaptopurine or methotrexate added to prednisone induces and maintains remission in steroid-dependent inflammatory bowel disease. Eur J Gastroenterol Hepatol 2000;12:1227-33.

14 Ardizzone S, Maconi G, Russo A, et al. Randomised controlled trial of azathioprine and 5 -aminosalicylic acid for treatment of steroid dependent ulcerative colitis. Gut 2006:55:47-53.

15 Oren R, Arber N, Odes S, et al. Methotrexate in chronic active ulcerative colitis: a double-blind, randomized, Israeli multicenter trial. Gastroenterology 1996;110:1416-21.

16 Cummings JR, Herlinger KR, Travis SP, et al. Oral methotrexate in ulcerative colitis. Aliment Pharmacol Ther 2005;21:385-9.

17 Fraser AG, Morton D, McGovern D, et al. The efficacy of methotrexate for maintaining remission in inflammatory bowel disease. Aliment Pharmacol Ther 2002;16:693-7.

18 Shibolet O, Regushevskaya E, Brezis M, et al. Cyclosporine for induction of remission in severe ulcerative colitis. Cochrane Database Syst Rev 2005; 25:CD004277.

19 Fernandez-Banares $F$, Bertran X, EsteveComas $M$, et al. Azathioprine is useful in maintaining long-term remission induced by intravenous cyclosporine in steroid-refractory severe ulcerative colitis. Am J Gastroenterol 1996:91:2498-9.

20 Campbell S, Ghosh S. Combination immunomodulatory therapy with cyclosporine and azathioprine in corticosteroid-resistant severe ulcerative colitis: the Edinburgh experience of outcome. Dig Liver Dis 2003;35:546-51.

21 Campbell S, Travis S, Jewell D. Ciclosporin use in acute ulcerative colitis: a long-term experience. Eur J Gastroenterol hepatol 2005:17:79-84.

22 Jarnerot G, Hertervig E, Friis-Liby I, et al. Infliximab as rescue therapy in severe to moderately severe ulcerative colitis: a randomized, placebo-controlled study. Gastroenterology 2005;128:1805-11.

23 Van Assche G, D'Haens G, Noman M, et al Randomized, double blind comparison of $4 \mathrm{mg} /$ $\mathrm{kg}$ versus $2 \mathrm{mg} / \mathrm{kg}$ intravenous cyclosporine in severe ulcerative colitis. Gastroenterology 2003;125:1025-31. could account for $14 \%$ of male and $20 \%$ of female cancer deaths in the USA. ${ }^{3}$ But getting a clear message from these studies can be difficult. Some papers report different associations for men versus women or for colon versus rectal cancer or for different measurements of overweight/obesity. It is reasonable to suppose that these types of risk factors might affect both sexes and parts of the colorectum in similar ways, although perhaps not to the same degree. So, do conflicting results reflect a true lack of association or are we missing the point by measuring the wrong parameters? Although the end points, such as cancer incidence and mortality, are simple to record accurately, measuring obesity and physical activity can be very difficult. There are no surrogate markers that can be easily measured in a blood test, for example. Weight, height, body mass index (BMI), waist circumference, hip circumference, waist to hip ratio, per cent body fat, adipose mass, and nonadipose mass are some of the more embarrassed by our glutton and sloth. The government is now trying to tackle the problem at its roots, focusing on "healthy" school meals and promoting exercise with the hope that fit and healthier adults. ${ }^{2}$ The decision to host the 2012 Olympics in London will be a further fillip for this policy.

There are now multiple studies which demonstrate an association between obesity, exercise, and colorectal cancer incidence and mortality. ${ }^{3-6}$ It has been estimated that overweight and obesity 
regularly measured indicators of obesity. But which is the most important or useful?

Simple obesity, such as that measured by BMI, may not be the most useful indicator of risk, but measurements of hip circumference (an indicator of general obesity) versus waist circumference and waist to hip ratio (indicators of central abdominal obesity) may be more useful. In the field of cardiovascular disease for example, blood pressure has been found to correlate closely with waist to hip ratio, independently of $\mathrm{BMI}^{7}$ and in the Framingham study central obesity was a better predictor of coronary artery disease than general obesity. ${ }^{8}$ In another study, a high BMI in adolescence was found to increase the subsequent risk of mortality from cancer in general, but this association was not found for colorectal cancer'; as discussed below, concerning another study, this does not necessarily mean that obesity is not relevant-if measures of abdominal obesity had been obtained, it is possible that they might have shown a correlation. Even harder to quantify than obesity is physical activity-how much, how often, how strenuous, and how sustained over a period of life might all be relevant. Research into these and other epidemiological factors rely almost entirely on massive cohorts of persons volunteering information about their lifestyle over many years.

Weight and exercise are connected and it is likely that for both there will be some shared mechanisms underlying their effects despite some of the differences in findings of epidemiological studies. One unifying hypothesis relates to insulin and regulation of energy metabolism. Diabetes and HbAlc concentrations are associated with increased risk of colorectal cancer ${ }^{10} 11$ and the role of insulin and its associated growth factors and binding proteins have been implicated in colorectal carcinogenesis. ${ }^{12}$ Recent analysis of two large American cohorts of health sector workers where detailed dietary and physical activity assessments had been made revealed a correlation between high glycaemic load, and fructose and sucrose ingestion to colorectal cancer risk in men but not in women. ${ }^{13}$ Taking this one step further, Slattery et al investigated whether polymorphisms in genes known to be involved in insulin related functions affected risk. ${ }^{14}$ Although they did not find an association, it is inevitable that genetic differences between individuals will be found that can explain the interaction between diet, exercise, obesity, and cancer susceptibility.

The paper by Haydon and colleagues ${ }^{15}$ in this issue of Gut is based on a large cohort study in the Australian state of Victoria-the Melbourne Collaborative Cohort Study (MCCS) - which has followed nearly 42000 people recruited in 1990-1994 (see page 62). A previous report from this group demonstrated an association between central adiposity (waist circumference and waist to hip ratio) and risk of colon cancer in men. ${ }^{16}$ Interestingly, after adjustment for fat free mass and waist to hip ratio, BMI was no longer found to be a risk factor. The current study takes a new slant on the topic and examines the relationship between exercise and body composition prior to the diagnosis of colorectal cancer and survival afterwards. The parameters measured were recorded at the subjects' entry into the study which was a median of 5.3 years prior to colorectal cancer diagnosis. As concerns obesity, BMI showed no correlation with survival; however there were significant relationships between both smaller waist circumference and lower per cent body fat with prolonged survival. Exercise, too, showed a positive effect, mainly confined to stage II and III tumours. The effects held true even after correcting for other confounding factors such as age, sex, tumour stage, or diagnosis soon after enrolment.

If confirmed by other studies, these results tell us something quite new, that one's state of health, even years before a serious diagnosis such as cancer, can alter its prognosis. What is remarkable is that a single baseline measurement can demonstrate such a significant effect. For physical activity, the authors classified "exercisers" as those who said that they took any exercise at least once a week over the preceding six months, even if it did not make them sweat or feel out of breath. Even this crude categorisation seems to be predictive of prognosis. No further information about exercise or body composition was collected at the time of diagnosis or afterwards, and one might imagine that a measurement closer to diagnosis would be even more strongly predictive. Interestingly, the benefits of leanness and activity seemed to impact mainly on the cancer related deaths in the affected individuals, as mortality from other causes was not reduced. This is surprising as one would expect a "healthier" individual to have lower mortality from other causes too, especially cardiovascular events.

The findings of this study are not completely clear cut. Exercise showed no correlation with survival in those with very early or metastatic disease, and the beneficial effects were seen mainly in proximal colon cancers. The effects of central adiposity were most significant for distal tumours and were independent of tumour stage. Epidemiologists involved in such studies are acutely aware of potential confounding factors that might lead to a false assumption that association of variables is causal. For example, could exercisers or lean individuals somehow be reporting their cancers at an earlier stage and so only appear to have a better prognosis? There is at least some evidence that this is probably not so. ${ }^{17}$

What are the implications of this study? Firstly, we must encourage more studies into the effects of body composition and exercise on cancer, and ensure that they examine not just BMI but measurements of central abdominal obesity, in particular waist circumference or waist to hip ratio. If proven, there should be an even greater impetus in favour of weight reduction and physical activity, which we already know are good for us. Secondly, we need to understand how and why body composition and exercise affect cancer risk. This will require more basic research into the genetics of obesity and metabolism, the cellular effects of exercise, and its effects on tumour initiation, progression, and metastasis. More difficult is the next step which is interventional research: can we prove that alteration in body composition and/ or taking more exercise can really benefit individuals and change their risk status? Would a programme of weight reduction and exercise in those just diagnosed with colorectal cancer benefit them or is it already too late ${ }^{18}$ There is some evidence, at least in women with colon cancer undergoing chemotherapy, that a high BMI worsens mortality (although interestingly possibly lowers the risk of chemotherapy toxicity) in patients with stage II and III cancer $^{19}$ although this does not rule out the effect predating the surgery. In other words, loosing weight after surgery might be of benefit. There is also hope that exercise after diagnosis of colorectal cancer might improve survival and decrease recurrence. ${ }^{20}$

In summary, physical activity and excess body mass seem to affect colorectal cancer (among many other benign and malignant conditions) in its different stages of development. Increasing adiposity and inactivity predispose to the development of cancer in the first place; they may adversely affect morbidity and mortality from surgery; and we now find from the study published in this issue of Gut that they predispose to a worse prognosis after diagnosis. There is a least some expectation that long term health and fitness programmes might reap benefits not only in terms of reducing colorectal cancer 
incidence but in prolonging survival even if bowel cancer does occur.

Gut 2006;55:8-10.

doi: $10.1136 /$ gut.2005.074419

Correspondence to: Mr N R Hall, Department of Surgery, Box 201, Addenbrooke's Hospital, Hills Rd, Cambridge CB2 2QQ, UK; nigel.r.hall@addenbrookes.nhs.uk

Conflict of interest: None declared.

\section{REFERENCES}

1 Nelson DE, Bland S, Powell-Griner E, et al. State trends in health risk factors and receipt of clinical preventive services among US adults during the 1990s. JAMA 2002; 287:2659-67.

2 Department of Health. Choosing a better diet-a food and health action plan. London: Stationery Office, 2005

3 Calle EE, Rodriguez C, Walker-Thurmond K, et al. Overweight, obesity, and mortality from cancer in a prospectively studied cohort of U.S. adults. NEngl J Med 2003;348:1625-38.

4 Davey Smith G, Shipley MJ, Batty GD, et al. Physical activity and cause-specific mortality in the Whitehall study. Public Health 2000;114(5):308-15.

5 Suadicani P, Hein HO, Gyntelberg F. Height, weight, and risk of colorectal cancer. An 18-year follow-up in a cohort of 5249 men.

Scand J Gastroenterol 1993;28:285-8.

6 Wei EK, Giovannucci E, Wu K, et al. Comparison of risk factors for colon and rectal cancer. Int J Cancer 2004; 108:433-42.

7 Canoy D, Luben R, Welch A, et al. Fat distribution, body mass index and blood pressure in 22,090 men and women in the Norfolk cohort of the European Prospective Investigation into Cancer and Nutrition (EPIC-Norfolk) study. J Hypertension 2004;22:2067-74.

8 Higgins M, Kannel W, Garrison R, et al. Hazards of obesity-the Framingham experience. Acta Med Scand 1988:723:23-36.

9 Okasha M, McCarron P, McEwen J, et al. Body mass index in young adulthood and cancer mortality: a retrospective cohort study. J Epidemiol Community Health 2002;56:780-4.

10 Khaw KT, Wareham N, Bingham S, et al. Preliminary communication: glycated hemoglobin, diabetes, and incident colorectal cancer in men and women: a prospective analysis from the European prospective investigation into cancer-Norfolk study. Cancer Epidemiol Biomarkers Prev 2004;13:915-19.

11 Nilsen TI, Vatten U. Prospective study of colorectal cancer risk and physical activity, diabetes, blood glucose and BMI: exploring the hyperinsulinaemia hypothesis. $\mathrm{Br} J$ Cancer 2001;84:417-22.

12 Sandhu MS, Dunger DB, Giovannucci EL. Insulin, insulin-like growth factor-I (IGF-I), IGF binding proteins, their biologic interactions, and colorectal cancer. J Natl Cancer Inst 2002;94:972-80
13 Michaud DS, Fuchs CS, Liu S, et al. Dietary glycemic load, carbohydrate, sugar, and colorectal cancer risk in men and women. Cancer Epidemiol Biomarkers Prev 2005; 14:138-47.

14 Slattery ML, Murtaugh M, Caan B, et al. Energy balance, insulin-related genes and risk of colon and rectal cancer. Int $J$ Cancer 2005; 115: 148-54.

15 Haydon AMM, Maclnnis RJ, English DR, et al. Effect of physical activity and body size on survival after diagnosis with colorectal cancer Gut 2006;55:62-7.

16 Maclnnis RJ, English DR, Hopper JL, et al. Body size and composition and colon cancer risk in men. Cancer Epidemiol Biomarkers Prev 2004; 13:553-9.

17 Slattery ML, Edwards SL, Samowitz W. Stage of colon cancer at diagnosis: implications for risk factor associations? Int J Epidemiol 1998;27:382-7

18 Brown JK, Byers T, Doyle C, et al. Nutrition and physical activity during and after cancer treatment: an American Cancer Society Guide for informed choices. CA Cancer J Clin informed choices.

19 Meyerhardt JA, Catalano PJ, Haller DG, et al. Influence of body mass index on outcomes and treatment-related toxicity in patients with colon carcinoma. Cancer 2003;98:484-95.

20 Meyerhardt JA, Heseltine D, Niedzwiecki D, et al. The impact of physical activity on patients with stage III colon cancer: Findings from Intergroup trial CALGB 89803. J Clin Oncol 2005;23(suppl 16):3534.

\section{Combined PET/CT colonography: is this the way forward?}

\section{A G Schreyer, R Kikinis}

\section{Combined whole body positron emission tomography/computed tomography (PET/CT) examination may be beneficial for staging in patients with colorectal cancer}

\section{"THE BEST OF BOTH WORLDS" (STAR TREK-THE NEXT GENERATION, SEASON 3, EPISODE 26, STARDATE 43989.1)} Computed tomography (CT) colonography is a recently introduced technique which is being investigated for several indications. Its role as a screening tool for polyp detection is still controversial. ${ }^{1-7}$ Most studies show that the method has a sensitivity of $>90 \%$ in detecting colorectal polyps of $10 \mathrm{~mm}$ or more in size. However, the influence of the scanner or visualisation hardware and software is not clear.8 ${ }^{9}$ Additionally, the learning curve for image interpretation is an important quality and cost factor for CT based colonography. ${ }^{1}$ Despite these concerns, the use of CT or magnetic resonance imaging (MRI) based colonography in patients with incomplete colonoscopy is becoming a more and more accepted examination method in experienced clinical centres. ${ }^{1011}$ The major downside of sectional radiological imaging such as CT and MRI is the lack of specific functional data. The only functional information in CT and standard MR imaging is contrast media uptake, which is a rather unspecific feature. On the other hand, functional imaging methods such as $\left[{ }^{18} \mathrm{~F}\right]$-fluoro-2-deoxyD-glucose-positron emission tomography (FDG-PET) are particularly accurate in staging primary and recurrent colorectal cancer, but suffer from inferior anatomical resolution. ${ }^{12-14}$ Consequently, it appears very appealing to integrate FDG-PET imaging into a high resolution multislice CT examination to have the best of both worlds in one comprehensive data set. ${ }^{15-18}$

In this issue of Gut, Veit and colleagues $^{19}$ present a feasibility study applying a whole body PET/CT protocol with additional preparation and distension of the colon, resulting in a comprehensive whole body PET/CT colonography examination (see page 68). Data acquisition was performed using a dual slice CT scanner with an integrated PET system. Studying 14 patients with suspected colorectal cancer, one additional colonic lesion in a patient with incomplete colonoscopy was detected. Lymph node staging proved to be correct in nine out of 11 patients. PET/CT identified increased glucose metabolism, suggesting malignancy in one patient where histopathology showed high grade intraepithelial dysplasia without cancerous growth. Moreover, six additional tumour sites (five of them previously unknown) such as liver metastases, breast cancer, hepatocellular carcinoma, pulmonary metastases, and thyroid carcinoma were identified. Based on this highly selected patient group, the authors conclude that combined PET/CT examination may be beneficial for patients with incomplete colonoscopy.

Even if this comprehensive and expensive combination of different imaging modalities is not suited as a screening tool for polyp detection, the idea of integrating different imaging methods into one comprehensive data representation is very appealing. It is cumbersome, inefficient, and fundamentally difficult to compare PET and CT scans just by mental fusion. Consequently, computer scientists have investigated various approaches towards 
the automatic or semi-automatic registration of image data sets. These may be classified as either rigid or non-rigid registration methods. Rigid registration essentially moves the two different three dimensional data sets using translations and rotations in space to find an optimal match. This method is effective for the registration of rigid anatomical regions, such as bones or the skull. But it may fail for non-rigid anatomical regions, such as the thorax, abdomen, or pelvis, if the patient breathes or is positioned differently within the two imaging devices or if the bowels move during the two examinations. One way to overcome this problem is dual scanning, which means having two different scanning modalities, such as PET and $\mathrm{CT}$, combined into one major apparatus, as described in by Veit and colleagues. ${ }^{19}$ Imaging can then be done in a very time efficient manner and bowel movements can be reduced during a 30 minute period using spasmolytic drugs.

The major drawbacks of this solution are the high investment cost as well as the limitation on certain combinations of modalities. There are enormous technical challenges to integrating, for example, an MRI scanner with a PET and CT scanner because of the magnetic effects. Non-rigid registration can somewhat overcome these problems by registering the surfaces of organs and structures within two data sets. ${ }^{20}$ This approach can even be used to register a standard anatomical three dimensional atlas to an individual patient by detecting and registering anatomical similarities. $^{21}$ This methodology has already been used in image guided neurosurgical procedures where brain shift is compensated for in order to register intraoperative imaging with preoperative MR or other image data. ${ }^{22}$ Even data registration between a prone and supine acquired CT colonography has been successfully performed using a nonrigid approach. ${ }^{23}$ Using this robust algorithm, a dual fly-through of the colon, presenting synchronised prone and supine scans, is feasible.

Digital integration of nearly every imaging modality in a radiological department offers the perfect foundation for practically every type of data fusion. MRI, CT, as well as ultrasound and flat panel radiography represent the most frequently used radiological tools providing primary digital source data. Theoretically, registration and comprehensive integration of these digital data into a connected three dimensional representation of the human body should be possible. ${ }^{24-26}$ In feasibility studies, even different sectional imaging data such as intraoperative laparoscopic ultrasound and three dimensional CT has been fused successfully ${ }^{27}$ using a standard laptop computer. Using a contour mapping framework, the fusion of two dimensional projection imaging such as fluoroscopy and three dimensional CT data can be achieved..$^{28}{ }^{29}$ Most of the above mentioned image fusion approaches should be considered as work in progress. However, the majority have the potential to be integrated into a comprehensive imaging framework in the near future.

According to the 19th century gestalt psychologist Wolfgang Metzger, ${ }^{30}$ the sum total is considered to be more than just the sum of its individual components. This can be adapted to radiological image data where the comprehensive mutual image information could increase diagnostic sensitivity and specificity. The present multimodality multisession diagnostic workup could be optimised by multiple scanning techniques, as described by Veit and colleagues, ${ }^{19}$ as well as by advanced software approaches which combine multimodality acquisition into one comprehensive three dimensional data set. Probably both methodologies will find their applications. Radiologists and computer scientists will continue to focus on this challenging subject and, to conclude with another Star Trek phrase, "to boldly go where no one has gone before".

Gut 2006;55:10-12.

doi: 10.1136/gut.2005.070870

\section{Authors' affiliations}

A G Schreyer, Department of Radiology, University Hospital Regensburg, Regensburg, Germany

R Kikinis, Department of Radiology, Surgical Planning Lab, Brigham and Women's Hospital, Harvard Medical School, Boston, MA, USA

Correspondence to: $\operatorname{Dr}$ A G Schreyer Correspondence to: Dr A G Schreyer,
Department of Radiology, University Hospital Regensburg, Franz-Josef-Strauss-Allee 11, 93053 Regensburg, Germany;

andreas.schreyer@klinik.uni-r.de

Conflict of interest: None declared.

\section{REFERENCES}

1 Pescatore P, Glucker T, Delarive J, et al. Diagnostic accuracy and interobserver agreement of CT colonography (virtual colonoscopy). Gut 2000;47:126-30.

2 Pickhardt PJ, Choi JR, Hwang I, et al. Computed tomographic virtual colonoscopy to screen for colorectal neoplasia in asymptomatic adults. N Engl J Med 2003;349:2191-200

3 van Gelder RE, Florie J, Stoker J. Colorectal cancer screening and surveillance with CT colonography: current controversies and obstacles. Abdom Imaging 2005;30:5-12.

4 Pickhardt PJ. By-patient performance characteristics of CT colonography: importance of polyp size threshold data. Radiology 2003;229:291-3.

5 Spinzi G, Belloni G, Martegani A, et al. Computed tomographic colonography and conventional colonoscopy for colon diseases: a prospective, blinded study. Am J Gastroenterol 2001:96:394-400.

6 Ajaj W, Pelster G, Treichel U, et al. Dark lumen magnetic resonance colonography: comparison with conventional colonoscopy for the detection of colorectal pathology. Gut 2003;52:1738-43.

7 Rockey DC, Paulson E, Niedzwiecki D, et al. Analysis of air contrast barium enema, computed tomographic colonography, and colonoscopy: prospective comparison. Lancet 2005;365:305-11

8 Hara AK, Johnson CD, MacCarty RL, et al. CT colonography: single- versus multi-detector row imaging. Radiology 2001;219:461-5.

9 Pickhardt PJ. Three-dimensional endoluminal CT colonography (virtual colonoscopy): comparison of three commercially available systems. AJR Am J Roentgenol 2003;181:1599-606.

10 Ajai W, Lavenstein TC, Pelster G, et al. MR colonography in patients with incomplete conventional colonoscopy. Radiology 2005;234:452-9.

11 Fenlon HM, Nunes DP, Clarke PD, et al. Colorectal neoplasm detection using virtual colonoscopy: a feasibility study. Gut 1998:43:806-11.

12 Rohren EM, Turkington TG, Coleman RE. Clinical applications of PET in oncology. Radiology 2004;231:305-32

13 Abdel-Nabi H, Doerr RJ, Lamonica DM, et al. Staging of primary colorectal carcinomas with fluorine-18 fluorodeoxyglucose whole-body PET: correlation with histopathologic and CT findings. Radiology 1998;206:755-60.

14 Huebner RH, Park KC, Shepherd JE, et al. A meta-analysis of the literature for whole-body FDG PET detection of recurrent colorectal cancer. J Nucl Med 2000;41:1177-89.

15 Lemke AJ, Niehues SM, Hosten N, et al. Retrospective digital image fusion of multidetector CT and 18F-FDG PET: clinical value in pancreatic lesions-a prospective study with 104 patients. J Nucl Med 2004;45:1279-86.

16 Schoder H, Yeung HW, Gonen M, et al. Head and neck cancer: clinical usefulness and accuracy of PET/CT image fusion. Radiology 2004;231:65-72.

17 Antoch G, Vogt FM, Freudenberg LS, et al. Whole-body dual-modality PET/CT and wholebody MRI for tumor staging in oncology. JAMA 2003;290:3199-206.

18 Beyer T, Antoch G, Blodgett T, et al. Dualmodality PET/CT imaging: the effect of respiratory motion on combined image quality in clinical oncology. Eur J Nucl Med Mol Imaging 2003;30:588-96.

19 Veit P, Kühle C, Beyer T, et al. Whole body positron emission tomography/computed tomography (PET/CT) tumour staging with integrated PET/CT colonography: technical feasibility and first experiences in patients with colorectal cancer. Gut 2006;55:68-73.

20 Crum WR, Hartkens T, Hill DL. Non-rigid image registration: theory and practice. $\mathrm{Br} J$ Radiol 2004;77:S1 40-53.

21 Lorenzen P, Prastawa M, Davis B, et al. Multimodal image set registration and atlas formation. Med Image Anal 2005 (in press).

22 Warfield SK, Talos F, Tei A, et al. Real-time registration of volumetric brain MRI by biomechanical simulation of deformation during image guided neurosurgery. Comput Visual Sci 2002:5:3-11.

23 Nain D, Haker S, Eric W, et al. Intra-patient prone to supine colon registration for synchronized virtual colonoscopy. Tokyo, Japan: M ICCAI 573-580, 2002

24 Verhey JF, Wisser J, Warfield SK, et al. Nonrigid registration of a $3 D$ ultrasound and a MR image data set of the female pelvic floor using a biomechanical model. Biomed Eng Online 2005;4:19.

25 Lange T, Eulenstein S, Hunerbein M, et al. Vesselbased non-rigid registration of MR/CT and $3 D$ ultrasound for navigation in liver surgery. Comput Aided Surg 2003;8:228-40.

26 Behrenbruch CP, Marias K, Armitage PA, et al. Fusion of contrast-enhanced breast MR and mammographic imaging data. Med Image Anal 2003;7:311-40. 
27 Ellsmere J, Stoll J, Wells W 3rd, et al. new visualization technique for laparoscopic ultrasonography. Surgery 2004;136:84-92.

28 Yezzi A, Zollei L, Kapur T. A variational framework for integrating segmentation and registration through active contours. Med lmage Anal 2003;7:171-85.

29 Zollei L, Fisher JW, Wells WM. A unified statistical and information theoretic framework for multi-modal image

Pancreatic stellate cells

\section{Pancreatic stellate cells: new kids* become mature}

\section{Pinzani}

\section{Vitamin A and its metabolites can reverse activation of culture activated pancreatic stellate cells and prevent ethanol induced pancreatic stellate cell activation}

${ }^{\mathrm{t}}$ is with great pleasure that I present to the readers of Gut this commentary accompanying the paper by McCarroll and colleagues ${ }^{1}$ published in this issue of the journal (see page 79). The field of pancreatic stellate cell (PSC) research has grown exponentially in the past five years and major advancements have been made since their first identification as a pathophysiological entity at the end of the 1990s. ${ }^{2}{ }^{3}$ In those years, research on hepatic stellate cells (HSCs) and on their role in liver fibrogenesis had reached an elevated degree of sophistication. Therefore, the possibility of isolating stellate cells from rodent or human pancreas led to an almost automatic introduction of PSCs into a new research area: the cellular and molecular mechanisms of pancreatic fibrogenesis.

Fibrosis in the pancreas is consequent to necrosis/apoptosis, inflammation, or duct obstruction. The initial event that induces fibrogenesis in the pancreas is an injury that may involve the interstitial mesenchymal cells, duct cells, and/or acinar cells. Damage occurring in any of these tissue compartments is associated with cytokine triggered transformation of resident fibroblasts/ pancreatic stellate cells into myofibroblasts and the subsequent production and deposition of extracellular matrix. The fibrogenic development depends on the site of injury and the involved tissue compartment. Deposition of excessive extracellular matrix is predominantly inter(peri)lobular (as in alcoholic chronic pancreatitis), periductal (as in hereditary pancreatitis), periductal and interlobular (as in autoimmune pancreatitis), or diffuse inter- and intralobular (as in obstructive chronic pancreatitis). In many ways, the development of pancreatic fibrosis recalls the

different models of progressive scarring observed in liver tissue following chronic parenchymal damage or bile duct obstruction. Accordingly, it is likely that the two basic profibrogenic mechanisms known to be involved in hepatic scarring are also involved in pancreatic fibrogenesis: (1) chronic activation of the wound healing process with persistent chronic inflammation and progressive substitution of the parenchyma with fibrillar extracellular matrix; and (2) direct profibrogenic and proinflammatory effects of reactive oxygen species and oxidative stress end products (see Pinzani and Rombouts ${ }^{4}$ for review).

However, there are two main differences due to the different structure and reactivity of the hepatic and pancreatic tissue. Firstly, hepatocytes are able to regenerate and enter a cycle of cell divisions until the original functional mass of the organ is restored. This process is activated through similar basic mechanisms in the presence of both acute and chronic damage. As a consequence, the hepatic fibrogenic process is characterised by an abundant regenerative component that leads to the final cirrhotic outcome (regenerative parenchymal nodules surrounded by fibrous rings). In contrast, pancreatic tissue is characterised by limited regenerative potential and, as a result of its prevalent enzymatic content, is prone to significant fluid extravasation and tissue oedema. In addition, pancreatic tissue is more sensible than liver tissue to abnormal pressure developing within the ductal system.

"Pinzani M. New kids on the block: pancreatic stellate cells enter the fibrogenesis world. Gut 1999:44:451-2. registration. Inf Process Med Imaging 2003;18:366-77

30 Metzger W. Certain implications in the concept of gestalt. Am J Psychol 1928;40:162-6.
The bulk of evidence produced in the past five years indicates that there are no major differences between the profibrogenic potential of HSCs and PSCs. Accordingly, PSCs undergo a process of activation and phenotypic modulation towards a "myofibroblast" phenotype following pathways previously described for HSCs. These include, for example, stimulation by proinflammatory cytokines, ${ }^{5}$ involvement of the peroxisome proliferator activated receptor (PPAR) $-\gamma^{6}$ and Rho kinase, ${ }^{7}$ and the key role of oxidative stress and related products. ${ }^{8}$ The only different stimulus leading to activation of PSC is the increase in pressure exerted on primary cell culture, an experimental condition aimed at simulating an increase in pressure within the pancreatic tissue as in the case of ductal obstruction. ${ }^{9}$ Although it is likely that such a stimulus would induce the same effect in HSC cultures, the information appears relevant due to the established closer clinical association between ductal abnormalities and the presence of pancreatic damage. Sustained activation of PSC and their full profibrogenic role are then sustained by the same factors described for HSCs, and in particular platelet derived growth factor, transforming growth factor $\beta 1$, and angiotensin II. ${ }^{10-13}$

In addition, as expected from previous research in HSC, the same intracellular signalling pathways mediating the biological effects of these factors are involved in PSC. ${ }^{14-16}$ Because of the possible major role of oxidative stress in pancreatic fibrogenesis, some studies have started delineating this aspect. ${ }^{17} 18$ Once again, the results of these studies lead to conclusions identical to those obtained by studies performed in liver tissue or in HSC cultures, and further studies in this direction are highly awaited. Finally, transcriptome analysis aimed at demonstrating whether or not HSCs and PSCs are part of the same lineage has shown that the two cell types are highly similar with minor organ specific variation, whose meaning should be further evaluated. ${ }^{19}$

All these new acquisitions on the biology of PSC are indeed of high technical and methodological value, particularly considering their rapid development. However, the scheme of development of this area of research had largely followed a track that lacks major originality (that is, most of the available knowledge on the pathogenic role of 
PSCs has been obtained using HSCs as a template rather than a term of comparison). In any case, it is true that knowledge of the biology of PSCs has reached a sound level of maturity, and research in this area is starting to move into regions more relevant for the understanding of the mechanisms that links chronic pancreatitis to pancreatic inflammation, fibrogenesis, and cancer. In this direction, it has recently been reported that activated PSCs express the protease activated receptor 2 which interacts with trypsin and tryptase, two key pancreatic enzymes involved in the pathogenesis of chronic pancreatitis. ${ }^{20}$ Trypsin and tryptase were able to induce PSC proliferation and collagen synthesis through activation of c-Jun N-terminal kinase and p38 mitogen activated protein kinase.

The potential contribution of PSCs to the development and progression of pancreatic cancer appears indeed fundamental and sound advancements have been made in this area. The first important observation is that malignant cells can actively alter the microenvironment of the pancreatic tissue by modulating the composition of the extracellular matrix in a tumour favourable way through synthesis and release of soluble factors. ${ }^{21}$ Accordingly, recent evidence suggests that pancreatic cancer promotes the activation/proliferation of PSCs and the consequent increase in extracellular matrix synthesis. ${ }^{22}{ }^{23}$ Marked accumulation of fibrillar extracellular matrix, and particularly collagen type I, in peritumoral areas leads to the so-called desmoplastic reaction, often observed in pancreatic cancer. PSCs have been shown to represent a key cellular component in this type of stromal reaction. ${ }^{24}$

Although the desmoplastic reaction is classically indicated as a phenomenon limiting the expansion of the cancer mass, there are data indicating that collagen type I is able to promote the malignant phenotype of pancreatic adenocarcinoma. ${ }^{25}$ It is therefore likely that PSCs can influence the organisation and progression of pancreatic cancer, providing key components of the tumour stroma. Along these lines, it is worth investigating the possible production of proteases and other factors involved in tumour invasion by PSCs. This area of investigation is now very active and major advances, potentially transferable to PSCs, have recently been made for HSCs. ${ }^{26}$ Finally, a recent important observation has been provided by a study demonstrating that pancreatic cancer cells are able to increase expression of cyclooxygenase 2 (COX-2) in PSCs, and COX-2 expression is associated with several human cancers, including pancreatic adenocarcinoma. ${ }^{27}$
The last topic worth addressing is the potential implications for therapy of chronic pancreatitis arising from the advances in PSC research. Firstly, in the context of the relevant role of PPAR- $\gamma$ in PSC activation, two studies have shown that troglitazone, a PPAR- $\gamma$ agonist, reduced the profibrogenic activity of PSCs and progression of chronic pancreatitis in mice. ${ }^{28}{ }^{29}$ Interestingly the antifibrogenic effect of troglitazone seemed to be independent of PPAR- $\gamma .^{28}$ Glitazones, pioglitazone in particular, are currently indicated as potential therapeutic agents for liver diseases such as chronic alcoholic and non-alcoholic steatohepatitis. $^{30-32}$ It is therefore relevant that the same class of drugs could be used to reduce fibrogenic progression in both the liver and pancreas in those patients in which the two organs are affected by the same aetiological agent.

Other pharmacological agents that have been shown to produce a potential antifibrogenic effect in PSC cultures or animal models of chronic pancreatitis include plant derived polyphenolic antioxidants such as epigallocatechin-3-gallate $^{33}$ and ellagic acid,,$^{34}$ and the trypsin inhibitor camostat mesilate. ${ }^{35} 36$

McCarroll and colleagues ${ }^{1}$ investigated the effect of retinol and its metabolites on the activation state of PSCs. They demonstrated that these compounds can reverse activation of culture activated PSCs and prevent ethanol induced PSC activation, both effects being mediated through the MAPK pathway. The study contains novel and original information and not just in the field of PSC biology. Indeed, several findings emerging from this work should be confirmed in HSCs which are clearly more involved in vitamin A metabolism and are similarly exposed to ethanol under conditions of chronic abuse. What is debatable about this otherwise excellent study is the title and the last paragraph in the discussion (that is, the possible use of retinoids for the treatment of pancreatic fibrosis). The possibility of employing retinoids for treating hepatic fibrosis in humans has been a key issue for some time since the beginning of the 1990s. However, this option was abandoned for two main reasons: (1) the need to chronically use very high doses in order to achieve less than $50 \%$ of the serum concentration effective in animal models and less than $1 \%$ of the concentration effective in cell cultures; and (2) the toxic effect of vitamin A accumulation, which is paradoxically able to induce extensive fibrosis and cirrhosis of the liver or non-cirrhotic portal hypertension. These concerns obviously apply to the proposed use for chronic pancreatitis.

In conclusion, I believe that the PSC area of research has become mature, and will develop in directions more relevant to the pathophysiology of the pancreas. A final warning for liver fibrosis researchers: be alerted, the kids have become adults!

Gut 2006;55:12-14.

doi: 10.1136/gut.2005.074427

Correspondence to: Dr M Pinzani, Dipartimento di Medicina Interna, Universitò degli Studi di Firenze, Viale GB Morgagni, 85, 50134 Firenze, Italy; m.pinzani@dmi.unifi.it

Conflict of interest: None declared.

\section{REFERENCES}

1 McCarroll JA, Phillips PA, Santucci N, et al. Vitamin A inhibits pancreatic stellate cell activation: implications for treatment of pancreatic fibrosis. Gut 2006;55:79-89.

2 Bachem MG, Schneider E, Gross H, et al. Identification, culture, and characterization of pancreatic stellate cells in rats and humans. Gastroenterology 1998; 115:421-32.

3 Apte MV, Haber PS, Applegate TL, et al. Periacinar stellate shaped cells in rat pancreas: identification, isolation, and culture. Gut 1998:43:128-33.

4 Pinzani M, Rombouts K. Liver fibrosis: from the bench to clinical targets. Dig Liver Dis 2004:36:231-42.

5 Apte MV, Haber PS, Darby SJ, et al. Pancreatic stellate cells are activated by proinflammatory cytokines: implications for pancreatic fibrogenesis. Gut 1999:44:534-41.

6 Masamune A, Kikuta K, Satoh M, et al. Ligands of peroxisome proliferator-activated receptorgamma block activation of pancreatic stellate cells. J Biol Chem 2002;277:141-7.

7 Masamune A, Kikuta K, Satoh M, et al. Rho kinase inhibitors block activation of pancreatic stellate cells. Br J Pharmacol 2003; 140:1292-302.

8 Apte MV, Wilson JS. Stellate cell activation in alcoholic pancreatitis. Pancreas 2003:27:316-20.

9 Watanabe S, Nagashio Y, Asaumi H, et al. Pressure activates rat pancreatic stellate cells. Am J Physiol Gastrointest Liver Physiol 2004:287:G1175-81.

10 Luttenberger T, Schmid-Kotsas A, Menke A, et al. Platelet-derived growth factors stimulate proliferation and extracellular matrix synthesis of pancreatic stellate cells: implications in pathogenesis of pancreas fibrosis. Lab Invest 2000;80:47-55.

11 Kordes C, Brookmann S, Haussinger D, et al. Differential and synergistic effects of plateletderived growth factor-BB and transforming growth factor-betal on activated pancreatic growth factor-betal on activated pancreatic
stellate cells. Pancreas 2005;31:156-67.

12 Reinehr R, Zoller S, Klonowski-Stumpe H, et al. Effects of angiotensin II on rat pancreatic stellate cells. Pancreas 2004;28:129-37.

13 Hama K, Ohnishi H, Yasuda H, et al. Angiotensin II stimulates DNA synthesis of rat pancreatic stellate cells by activating ERK through EGF receptor transactivation. Biochem Biophys Res Commun 2004;315:905-11.

14 Jaster R, Sparmann G, Emmrich J, et al. Extracellular signal regulated kinases are key mediators of mitogenic signals in rat pancreatic stellate cells. Gut 2002;51:579-84.

15 Ohnishi H, Miyata T, Yasuda H, et al. Distinct roles of Smad2-, Smad3-, and ERK-dependent pathways in transforming growth factor-beta 1 regulation of pancreatic stellate cellular functions. J Biol Chem 2004;279:8873-8.

16 McCarroll JA, Phillips PA, Kumar RK, et al. Pancreatic stellate cell migration: role of the phosphatidylinositol 3-kinase(PI3-kinase) pathway. Biochem Pharmacol 2004;67:1215-25

17 Casini A, Galli A, Pignalosa P, et al. Collagen type I synthesized by pancreatic periacinar stellate cells (PSC) co-localizes with lipid 
peroxidation-derived aldehydes in chronic alcoholic pancreatitis. J Pathol 2000;192:81-9.

18 Kikuta K, Masamune A, Satoh M, et al. 4 Hydroxy-2, 3-nonenal activates activator protein 1 and mitogen-activated protein kinases in rat pancreatic stellate cells. World J Gastroenterol 2004:10:2344-51.

19 Buchholz M, Kestler HA, Holzmann K, et al. Transcriptome analysis of human hepatic and pancreatic stellate cells: organ-specific variations of a common transcriptional phenotype. J Mol Med 2005;83:795-805.

20 Masamune A, Kikuta K, Satoh M, et al. Protease-activated receptor-2-mediated proliferation and collagen production of rat pancreatic stellate cells. J Pharmacol Exp Ther 2005;312:651-8.

21 Koninger J, Giese T, di Mola FF, et al. Pancreatic tumor cells influence the composition of the extracellular matrix. Biochem Biophys Res Commun 2004;322:943-9.

22 Yoshida S, Yokota T, Ujiki M, et al. Pancreatic cancer stimulates pancreatic stellate cell proliferation and TIMP-1 production through the MAP kinase pathway. Biochem Biophys Res Commun 2004;323:1241-5.

23 Bachem MG, Schunemann M, Ramadani M, et al. Pancreatic carcinoma cells induce fibrosis by stimulating proliferation and matrix synthesis of stellate cells. Gastroenterology 2005; 128:907-21.

24 Apte MV, Park S, Phillips PA, et al. Desmoplastic reaction in pancreatic cancer role of pancreatic stellate cells. Pancreas 2004:29:179-87.

25 Armstrong T, Packham G, Murphy LB, et al. Type I collagen promotes the malignant phenotype of pancreatic ductal adenocarcinoma. Clin Cancer Res 2004; 10:7427-37.

26 Mazzocca A, Coppari R, De Franco R, et al. A secreted form of ADAM9 promotes carcinoma invasion through tumor-stromal interactions. Cancer Res 2005;65:4728-38.

27 Yoshida S, Ujiki $M$, Ding XZ, et al. Pancreatic stellate cells (PSCs) express cyclooxygenase-2 (COX-2) and pancreatic cancer stimulates COX-2 in PSCs. Mol Cancer 2005:4:27.

28 Shimizu K, Shiratori K, Kobayashi M, et al. Troglitazone inhibits the progression of chronic pancreatitis and the profibrogenic activity of pancreatic stellate cells via a PPARgammaindependent mechanism. Pancreas 2004;29:67-74

29 Van Westerloo DJ, Florquin S, de Boer AM, et al. Therapeutic effects of troglitazone in experimental chronic pancreatitis in mice. Am J Pathol 2005; 166:721-8.
30 Tomita K, Azuma T, Kitamura N, et al Pioglitazone prevents alcohol-induced fatty liver in rats through up-regulation of c-Met. Gastroenterology 2004;126:873-85.

31 Ohata M, Suzuki H, Sakamoto K, et al Pioglitazone prevents acute liver injury induced by ethanol and lipopolysaccharide through the suppression of tumor necrosis factor-alpha. Alcohol Clin Exp Res 2004;28(suppl 8):139-44S

32 Marchesini G, Marzocchi R, Agostini F, et al. Nonalcoholic fatty liver disease and the metabolic syndrome. Curr Opin Lipidol 2005;16:421-7.

33 Masamune A, Kikuta K, Satoh M, et al. Green tea polyphenol epigallocatechin-3-gallate blocks PDGF-induced proliferation and migration of rat pancreatic stellate cells. World J Gastroenterol 2005; 11:3368-74.

34 Masamune A, Satoh M, Kikuta K, et al. Ellagic acid blocks activation of pancreatic stellate cells Biochem Pharmacol 2005;70:869-78.

35 Gibo J, Ito T, Kawabe K, et al. Camostat mesilate attenuates pancreatic fibrosis via inhibition of monocytes and pancreatic stellate cells activity. Lab Invest 2005;85:75-89.

36 Emori $\mathrm{Y}$, Mizushima T, Matsumura N, et al. Camostat, an oral trypsin inhibitor, reduces pancreatic fibrosis induced by repeated administration of a superoxide dismutase inhibitor in rats. $J$ Gastroenterol Hepatol 2005:20:895-9.

\section{bmjupdates+}

bmiupdates+ is a unique and free alerting service, designed to keep you up to date with the medical literature that is truly important to your practice.

bmjupdates+ will alert you to important new research and will provide you with the best new evidence concerning important advances in health care, tailored to your medical interests and time demands.

Where does the information come from?

bmjupdates+ applies an expert critical appraisal filter to over 100 top medical journals A panel of over 2000 physicians find the few 'must read' studies for each area of clinical interest

Sign up to receive your tailored email alerts, searching access and more...

www.bmjupdates.com 